\title{
Harmine Hydrochloride Triggers G2/M Cell Cycle Arrest and Apoptosis in HCT116 Cells through ERK and PI3K/AKT/mTOR Signaling Pathways
}

\author{
Gi Dae Kim \\ Department of Food and Nutrition, Kyungnam University, Gyeongnam 51767, Korea
}

\begin{abstract}
Colorectal carcinoma (CRC) is one of the most common and aggressive malignant carcinomas. There is a pressing need to develop naturally derived novel drugs with minimal side effects for treatment of CRC. In this study, we aimed to investigate the anticancer effects of harmine hydrochloride ( $\mathrm{HMH})$, a hydrophilic and stable substance that is easily absorbed by tissues and similar to harmine, and the underlying mechanism of action in human CRC HCT116 cells. $\mathrm{HMH}$ inhibited the growth, colony formation, and migration ability of HCT116 cells. Additionally, HMH induced G2 cell cycle arrest by reducing expression of $\mathrm{p}-\mathrm{cdc} 2$, cdc2, and cyclin B1, proteins that regulate the G2/M phase, and expression of $\mathrm{Rb}$, a protein that regulates cell proliferation, in a dose-dependent manner. HMH mediated apoptosis by downregulating expression of apoptotic proteins (such as caspase-3, caspase-9, and PARP) and the anti-apoptotic protein Bcl-2 and by inducing expression of Bax, a pro-apoptotic protein. Furthermore, HMH reduced the levels of p-ERK, p-PI3K, p-AKT, and p-mTOR in HCT116 cells, and significantly inhibited p-ERK and p-AKT expression in cells treated with of HMH and PD98059, an ERK inhibitor, or LY294002, an AKT inhibitor $(P<0.05$ and $P<0.01)$. These results demonstrate the inhibitory effect of $\mathrm{HMH}$ on cell proliferation and migration through inducing apoptosis by inhibiting ERK and PI3K/AKT/ mTOR signaling pathways, indicating its potential therapeutic applications in CRC.
\end{abstract}

Keywords: apoptosis, ERK, G2/M, harmine hydrochloride, PI3K/AKT/mTOR

\section{INTRODUCTION}

Colorectal cancer (CRC) is one of the most common and aggressive malignant carcinomas (Torre et al., 2015). CRC is commonly treated by surgery or chemotherapy; however, chemotherapy is often ineffective and is associated with several side effects (Kuebler et al., 2007). Therefore, it is imperative to explore new approaches for treatment of CRC, including novel drugs derived from natural products that have minimal side effects.

Mitogen-activated protein kinases (MAPKs) regulate various cellular activities, such as cell proliferation, differentiation, migration, apoptosis, survival, inflammation, and innate immunity (Turjanski et al., 2007; Peti and Page, 2013). MAPKs, including c-Jun $\mathrm{NH}_{2}$-terminal kinase (JNK), p38 MAPK, and extracellular signal-regulated kinase (ERK), are serine-threonine protein kinases. The JNK and p38 MAPK signaling pathways are activated by various types of cellular stress such as oxidative stress, differentiation, apoptosis, genotoxicity, and osmotic stress, and microbial components such as bacterial lipopolysaccharides and inflammatory cytokines including tumor necrosis factor- $\alpha$ and interleukin-1 $\beta$ (Arthur and Ley, 2013; Sabio and Davis, 2014). The ERK signaling pathway plays a central role in cancer cell proliferation and metastatic progression (Das Thakur and Stuart, 2014).

The phosphoinositide 3-kinase (PI3K)/protein kinase B (AKT)/mammalian target of rapamycin (mTOR) pathway is involved in regulation of physiological processes such as cell proliferation, growth, survival, adhesion, motility, migration, metabolism, and angiogenesis. The pathway is also involved in various pathological processes, such as metastasis and the development of colorectal (PapadatosPastos et al., 2015), breast (Qin et al., 2018), liver (GolobSchwarzl et al., 2007), and pancreatic cancers (Murthy et al., 2018). Hyperactivation of the PI3K/AKT/mTOR signaling pathway has been reported in CRC (Kang et al., 2017). Therefore, metastasis, drug resistance, and cancer stemness, which mark the start of cancer, and the PI3K/ AKT/mTOR pathway are potential targets for CRC treat- 
ment (Bahrami et al., 2018).

Natural products have drawn the attention of researchers for several decades because of their anticancer properties (Mukherjee et al., 2001; McChesney, 2002). Harmine [7-methoxy-1-methyl-9H-pyrido(3,4-b)indole] is a $\beta$-carboline alkaloid extracted from the seeds of Peganum harmala L., a herbal plant that grows in dry regions such as the Middle East and certain regions in China. These seeds have been widely used in home remedies due to their anti-inflammatory and antitumor activities (Newman and Cragg, 2016). While harmine has remarkable pharmacological properties, its use has been considerably restricted owing to its low bioavailability and side effects. Although research is being conducted on harmine hydrochloride (HMH) (Liu et al., 2013; Zhang et al., 2016), studies on the mechanism of action of stable, anticancer $\mathrm{HMH}$ in CRC are lacking.

In the present study, we investigated the anticancer effects and mechanism of action of HMH, which is hydrophilic, stable, and easily absorbed by tissues. HMH exhibits the same characteristics as harmine in human CRC HCT116 cells (Zhang et al., 2020). We observed that HMH inhibits the growth of HCT116 cells by suppressing ERK and PI3K/AKT/mTOR pathways, consequently inducing cell cycle arrest and apoptosis.

\section{MATERIALS AND METHODS}

\section{Materials}

HMH (Fig. 1A; Sigma-Aldrich Co., St. Louis, MO, USA) was dissolved in 100\% dimethyl sulfoxide (DMSO). A 50 $\mathrm{mmol} / \mathrm{L}$ stock solution of $\mathrm{HMH}$ was prepared and stored as small aliquots at $-20^{\circ} \mathrm{C}$ until needed. DMSO, 3-(4,5dimethylthiazol-2-yl)-2,5-diphenyltetrazolium bromide (MTT), and horseradish peroxidase (HRP)-conjugated anti-rabbit and anti-mouse antibodies were purchased from Sigma-Aldrich, an apoptosis detection kit was purchased from BD Biosciences (Franklin Lakes, NJ, USA), and 2,7dichlorofluorescein (DCF) diacetate $\left(\mathrm{H}_{2} \mathrm{DCFDA}\right)$ was purchased from Molecular Probes (Invitrogen, Carlsbad, CA, USA). Phospho-specific anti-JNK, anti-p38, anti-ERK, anti-PI3K, anti-AKT, and anti-mTOR antibodies, anticaspase-3, anti-caspase-9, anti-poly(ADP-ribose) polymerase (PARP), anti-Bax, anti-Bcl-2, anti-JNK, anti-p38, anti-ERK, anti-PI3K, anti-AKT, and anti-mTOR specific antibodies, the ERK inhibitor PD98059, and the AKT inhibitor LY294002 were purchased from Cell Signaling Technology (Danvers, MA, USA). HRP-conjugated $\beta$-actin, p53, p21, p-cdc2, cdc2, cyclin B1, and Rb antibodies were purchased from Santa Cruz Biotechnology (Santa Cruz, CA, USA).

\section{Cell culture}

HCT116 human CRC cells were purchased from the American Type Culture Collection (Rockville, MD, USA) and cultured in Roswell Park Memorial Institute (RPMI)1640 medium containing $10 \%$ fetal bovine serum (FBS) and $1 \%$ antibiotics-antimycotics at $37^{\circ} \mathrm{C}$ in a $5 \% \mathrm{CO}_{2}$ incubator.

\section{Cell viability analysis}

MTT assays were used to measure the viability of HCT 116 cells following treatment with HMH. HCT116 cells $\left(5 \times 10^{3}\right.$ cells $\left./ \mathrm{mL}\right)$ were seeded into 96 -well plates and incubated overnight. The medium was subsequently re-
A<smiles>COc1ccc2c(c1)[nH]c1c(C)nccc12</smiles>

C

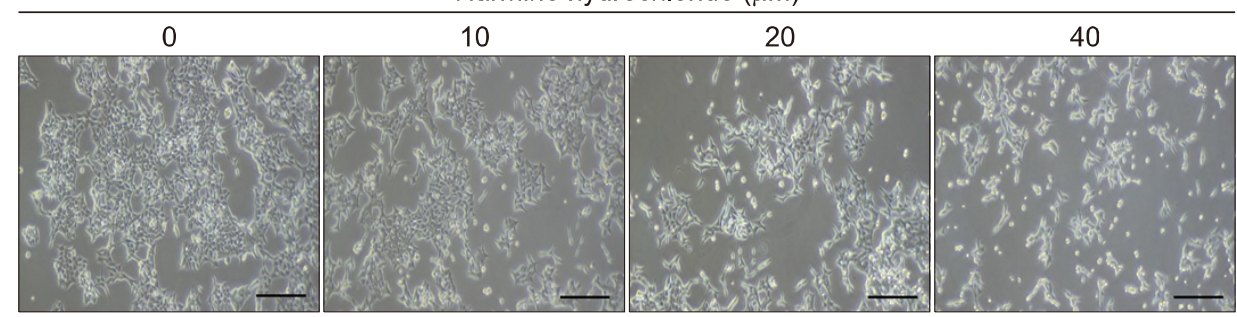

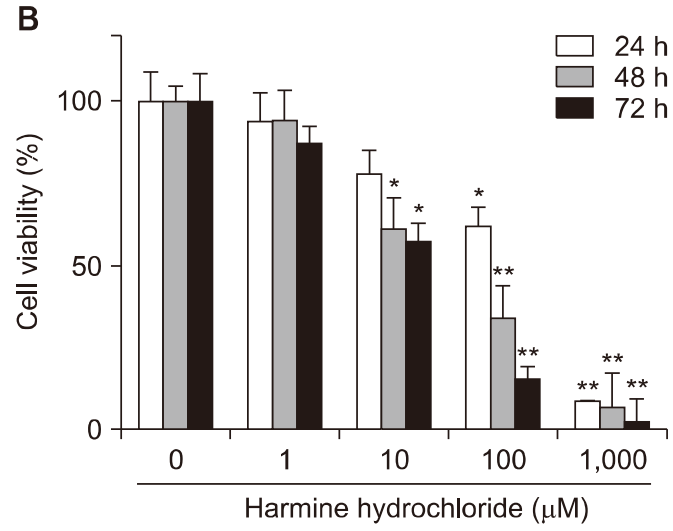
. as mean $\pm S D$, and analyze by Student's t-test $\left({ }^{*} P<0.05\right.$ and ${ }^{* *} P<0.01$ vs. the control group). (C) Morphological changes. $\mathrm{HMH}$ inhibited growth of HCT116 cells in a dose-dependent manner. Cell morphology was visualized by inverted microscopy (×200). Scale bar, $50 \mu \mathrm{m}$. MTT, 3-(4,5-dimethylthiazol-2-yl)2,5-diphenyltetrazolium bromide. 
placed with fresh RPMI-1640 medium supplemented with $0 \sim 1,000 \mu \mathrm{M}$ HMH for $24 \sim 72 \mathrm{~h}$. Following incubation, $20 \mu \mathrm{L}$ of MTT $(5 \mathrm{mg} / \mathrm{mL})$ reagent was added to each well, and plates was incubated for $3 \sim 4 \mathrm{~h}$. The medium was removed, and each well was treated with $100 \mu \mathrm{L}$ of DMSO to stop the reactions. Optical density was measured at $570 \mathrm{~nm}$ using a Synergy HTX plate reader (BioTek Instruments Inc., Winooski, VT, USA), and the data were analyzed using Gen5 software (BioTek Instuments Inc.).

\section{Wound healing assay for cell migration analysis Approximately $5 \times 10^{5}$ cells were seeded into a six-well plates and incubated for $24 \mathrm{~h}$. Cells were artificially wounded using a P20 pipette tip, the cell monolayer rinsed with fresh medium to remove dead cells, and cells were treated with $0 \sim 40 \mu \mathrm{M} \mathrm{HMH}$ in fresh medium con- taining $1 \%$ FBS for $24 \sim 72 \mathrm{~h}$. Images were obtained us- ing an inverted microscope equipped with a camera during the $24 \sim 72 \mathrm{~h}$ of incubation. Wound healing areas were measured using ImageJ software (National Institutes of Health, Bethesda, MD, USA).}

\section{Colony-formation assays}

Cells were plated at a density of 1,000 cells/well in a sixwell plates with $2 \mathrm{~mL}$ of RPMI- 1640 medium containing $10 \%$ FBS. Cells were incubated for $24 \mathrm{~h}$ in RPMI-1640 medium containing varying concentrations of $\mathrm{HMH}$ at $37^{\circ} \mathrm{C}$ in a $5 \% \mathrm{CO}_{2}$ incubator, and the medium was replaced with fresh medium without HMH every $3 \sim 4$ days. Colony formation was examined after 14 days of incubation. Then, colonies ( $>50$ cells) were fixed in methanol for $15 \mathrm{~min}$, stained with $0.1 \%$ crystal violet for $10 \mathrm{~min}$, and counted under a microscope (FV500, Olympus, Tokyo, Japan).

\section{Flow cytometry for cell cycle distribution analysis}

Cells were seeded in 100-mm culture plates and incubated for $24 \mathrm{~h}$. After ensuring that the cell density was $\geq 70 \%$, cells were treated with $0 \sim 40 \mu \mathrm{M} \mathrm{HMH}$ for $48 \mathrm{~h}$. Subsequently, cells were harvested with trypsin/ethylenediaminetetraacetic acid and fixed in $70 \%$ cold ethanol overnight. The fixed cells were centrifuged at 5,000 rpm at $4^{\circ} \mathrm{C}$ for $5 \mathrm{~min}$, washed, and incubated with RNase A $(50 \mu \mathrm{g} / \mathrm{mL})$ at $37^{\circ} \mathrm{C}$ for $30 \mathrm{~min}$ for cell cycle analysis. Cells were stained with $50 \mu \mathrm{g} / \mathrm{mL}$ propidium iodide (PI) at $37^{\circ} \mathrm{C}$ for $30 \mathrm{~min}$, and the DNA content was analyzed using CellQuest and a FACS Vantage SE flow cytometer (BD Biosciences).

\section{Cell apoptosis analysis}

Cell apoptosis assays were performed using HCT116 cells treated with HMH for $48 \mathrm{~h}$, according to the protocol provided by the Annexin V-fluorescein isothiocyanate (FITC) apoptosis detection kit (BD Biosciences). Cells were prepared at a density of $1 \times 10^{5}$ cells $/ \mathrm{mL}$ in binding buffer and incubated with Annexin V-FITC and PI in the dark for 30 min. The DNA content of the stained cells was analyzed using the CellQuest Software and a FACS Vantage SE flow cytometer (Becton Dickinson, Heidelberg, Germany).

\section{Measurement of intracellular reactive oxygen species (ROS) accumulation}

Intracellular ROS production was measured using the fluorescent dye ( $\mathrm{H}_{2} \mathrm{DCFDA}$, Molecular Probe, Invitrogen). After treatment with $0 \sim 40 \mu \mathrm{M} \mathrm{HMH}$ for $48 \mathrm{~h}$, cells were washed twice, stained with $20 \mu \mathrm{M} \mathrm{H}_{2} \mathrm{DCFDA}$ for $30 \mathrm{~min}$, and washed a further two times. $\mathrm{H}_{2}$ DCFDA reacts with ROS to form DCF, a fluorescent compound (Yoon et al., 2018). The amount of intracellular DCF was measured using flow cytometry (Becton Dickinson).

\section{Determination of protein expression by Western blotting}

Cells were treated with $\mathrm{HMH}(0,10,20$, and $40 \mu \mathrm{M})$ for $48 \mathrm{~h}$, then the proteins were extracted using PRO-PREP Protein Extraction Solution containing protease inhibitors and phosphatase inhibitors (Roche Diagnostics GmbH, Manheim, Germany) at $4^{\circ} \mathrm{C}$ for $30 \mathrm{~min}$. The extracted proteins were centrifuged at $4^{\circ} \mathrm{C}$ and $13,000 \mathrm{rpm}$ for 30 min. Protein samples $(40 \mu \mathrm{g})$ were then separated using $6 \% \sim 12 \%$ sodium dodecyl sulfate polyacrylamide gel electrophoresis and transferred onto polyvinylidene fluoride membranes (Bio-Rad Laboratories Inc., Hercules, CA, USA). The membranes were blocked with $5 \%$ bovine serum albumin (BSA) (AMRESCO, Cleveland, $\mathrm{OH}$, USA) prepared in Tris-buffered saline (TBS) with $0.1 \%$ Tween 20 (TBS-T) for $1 \mathrm{~h}$ and subsequently incubated with a primary antibodies $(1: 500 \sim 1: 1,000)$ diluted with $5 \%$ BSA at $4^{\circ} \mathrm{C}$ overnight. Next, the membranes were washed four times (3 min each) with TBS-T. After washing, the membranes were incubated with HRP-conjugated anti-rabbit or anti-mouse secondary antibodies $(1: 1,000)$ for $1 \mathrm{~h}$ at room temperature, and reactions were detected using an Advanced Electrochemiluminescence Western Blot Detection Kit (Amersham, Uppsala, Sweden).

\section{Statistical analyses}

Data are presented as mean \pm SD for the indicated number of independent experiments. Statistical significance $(P<0.05)$ was determined using Student's $t$-test for paired data. Statistical analyses were performed using IBM SPSS for Windows (version 23.0; IBM Co., Armonk, NY, USA). 


\section{RESULTS}

\section{HMH inhibits growth of HCT116 cells}

To investigate whether HMH effectively inhibits growth of human CRC cells, HCT116 cells were treated with $\mathrm{HMH}$ at varying concentrations $(0 \sim 1,000 \mu \mathrm{M})$ for $24 \sim$ $72 \mathrm{~h}$, and cell growth was examined. Following 24, 48, and $72 \mathrm{~h}$ of treatment, the $\mathrm{IC}_{50}$ values of $\mathrm{HMH}$ in HCT 116 cells were $125.5,58.2$, and $37.8 \mu \mathrm{M}$, respectively (Fig. 1B). Cell growth was significantly inhibited after 24 , 48 , and $72 \mathrm{~h}$ of $\mathrm{HMH}$ treatment at concentrations $\geq 100$ $\mu \mathrm{M}(P<0.05$ and $P<0.01$, respectively). Based on these $\mathrm{IC}_{50}$ values, we examined morphological changes to HCT 116 cells after treatment with $\mathrm{HMH}$ at concentrations of up to $40 \mu \mathrm{M}$ to determine the concentration at which HMH induced low cytotoxicity and high biological activity (Fig. 1C).

\section{HMH inhibits cell migration and colony formation}

Scratches were created on $70 \% \sim 80 \%$ confluent monolayers of HCT116 cells grown in culture dishes. FBS concentrations in the medium were reduced from $10 \%$ to $1 \%$, and cell migration was examined after treatment with varying concentrations of $\mathrm{HMH}(0 \sim 40 \mu \mathrm{M})$ for 48 h. The wound healing area was $3.2 \%$ in the $40 \mu \mathrm{M} \mathrm{HMH}$ treatment group versus $63.1 \%$ in the control group, in- dicating significant inhibition of cell migration after $\mathrm{HMH}$ treatment (Fig. 2A and 2C).

To investigate the inhibitory effect of $\mathrm{HMH}$ on colony formation, we treated HCT116 cells with varying concentrations of HMH for $24 \mathrm{~h}$. The medium containing $\mathrm{HMH}$ was replaced with fresh medium without $\mathrm{HMH}$, and the cells were cultured for a further 14 days. Colony formation was examined (Fig. 2B and 2D), and the number of colonies was observed to be significantly reduced by $95 \%$ in the group treated with $40 \mu \mathrm{M}$ HMH compared to the control group $(P<0.001)$.

\section{HMH induces $\mathrm{G} 2 / \mathrm{M}$ cell cycle arrest and apoptosis}

We examined the regulatory effect of HMH on HCT116 cell cycle progression because HMH was found to inhibit cell proliferation, migration, and colony formation in previous experiments. HCT116 cells were treated with $\mathrm{HMH}$ ( 0 to $40 \mu \mathrm{M}$ ) for $48 \mathrm{~h}$, and the distribution of the cell cycle stages was examined. A dose-dependent reduction was observed in the distribution of cells in the G0/G1 phase. The proportion of cells in the G2/M phase was $61.61 \%$ in the $40 \mu \mathrm{M}$ HMH treated group versus $13.71 \%$ in the control group (Fig. 3A and 3B). Western blotting was performed to examine the regulatory proteins in the G2/M phase. HMH increased expression of $\mathrm{p} 53$ and $\mathrm{p} 21$, which regulate the cell cycle, and reduced expression of
A

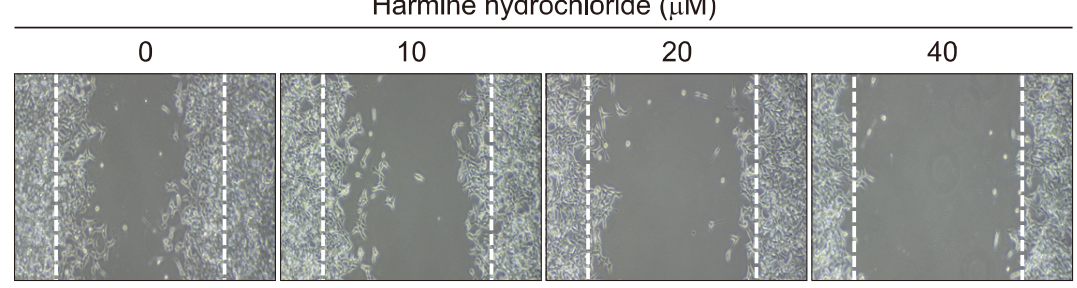

C

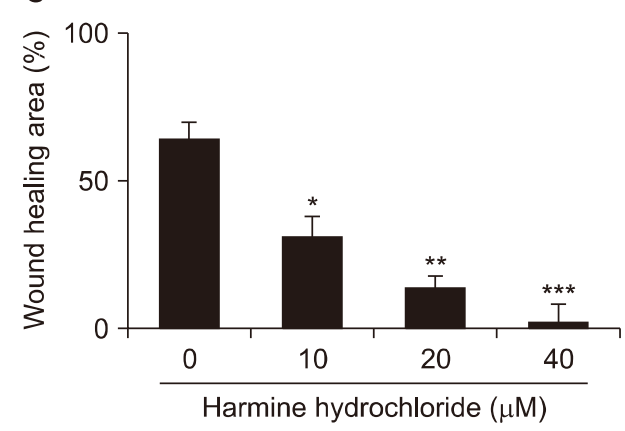

D

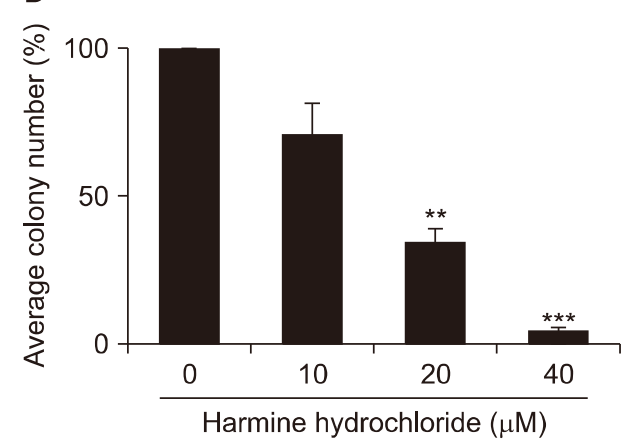

Fig. 2. Effect of harmine hydrochloride $(\mathrm{HMH})$ on migration and the colony-formation ability of HCT116 cells. (A) Scratches were made to confluent cell monolayers in six-well plates, cells were treated with $\mathrm{HMH}(0 \sim 40 \mu \mathrm{M})$ for $48 \mathrm{~h}$, and migration areas were measured. (B) Cells were seeded onto a six-well plate and treated with $\mathrm{HMH}$ at varying concentrations $(0 \sim 40 \mu \mathrm{M})$ for $24 \mathrm{~h}$. The medium was replaced with fresh medium every $3 \sim 4$ days during a 14-day culture period. After examining colony formation, cells were fixed in methanol and stained with $0.5 \%$ crystal violet. ( $C$ and D) Cells were examined under a microscope, and wound areas and the number of colonies determined using ImageJ. Values are presented as mean $\pm \mathrm{SD} .{ }^{*} P<0.05,{ }^{* *} P<0.01$, and ${ }^{* * *} P<0.001$ vs. control. 
A

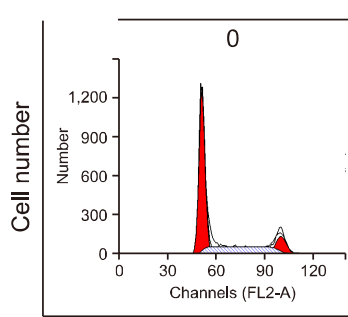

Harmine hydrochloride $(\mu \mathrm{M})$

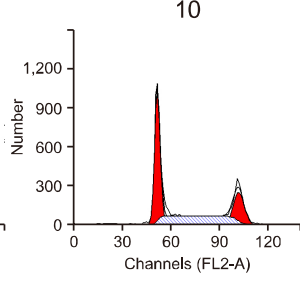

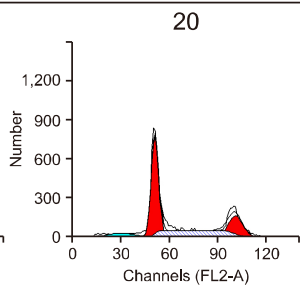

DNA content

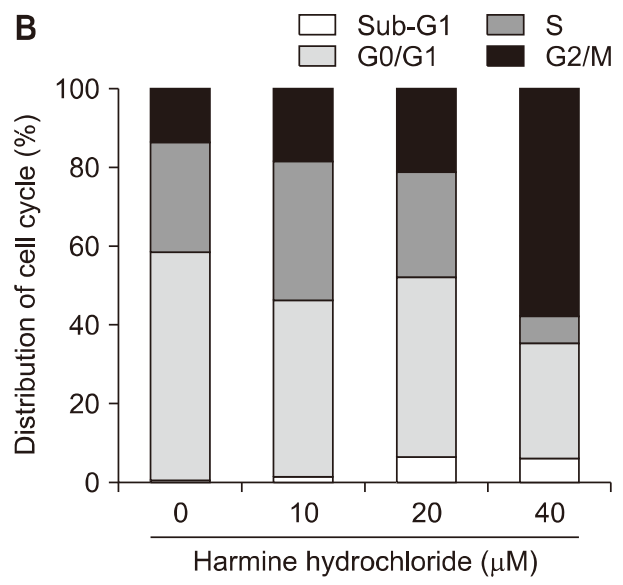

A

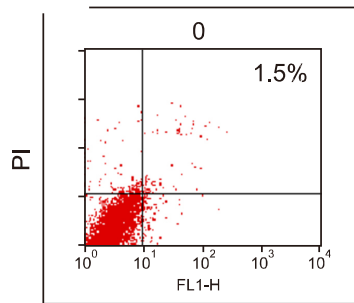

C

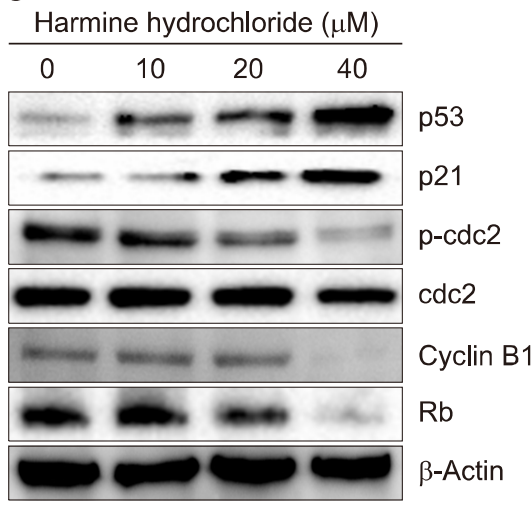

Fig. 3. Effect of harmine hydrochloride (HMH) on HCT116 cell cycle progression. (A) HCT116 cells were treated with $\mathrm{HMH}(0,10,20$, and 40 $\mu \mathrm{M})$ for $48 \mathrm{~h}$ and stained with propidium iodide. Flow cytometric analysis was performed to evaluate cell cycle progression. (B) Distribution of cells in the $\mathrm{GO} / \mathrm{G} 1, \mathrm{~S}$, and $\mathrm{G} 2 / \mathrm{M}$ phases following $\mathrm{HMH}$ treatment. $\mathrm{HMH}$ induced G2/M cell cycle arrest in a dose-dependent manner. (C) Western blotting was performed to examine expression of proteins associated with the G2/M phase, such as p53, p21, p-cdc2, cdc2, cyclin B, and $\mathrm{Rb}$.

Harmine hydrochloride $(\mu \mathrm{M})$

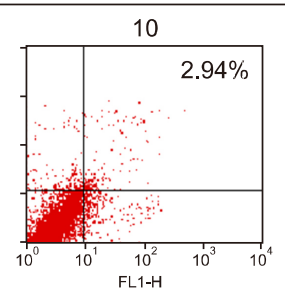

C

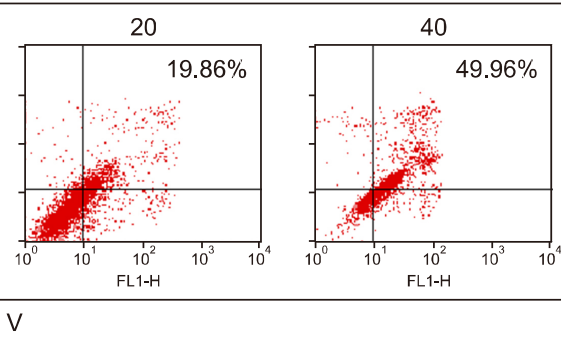

B

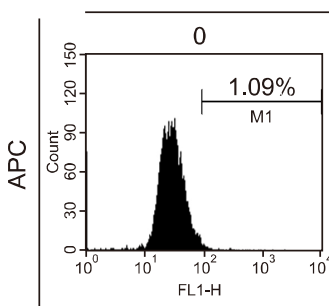

Harmine hydrochloride $(\mu \mathrm{M})$

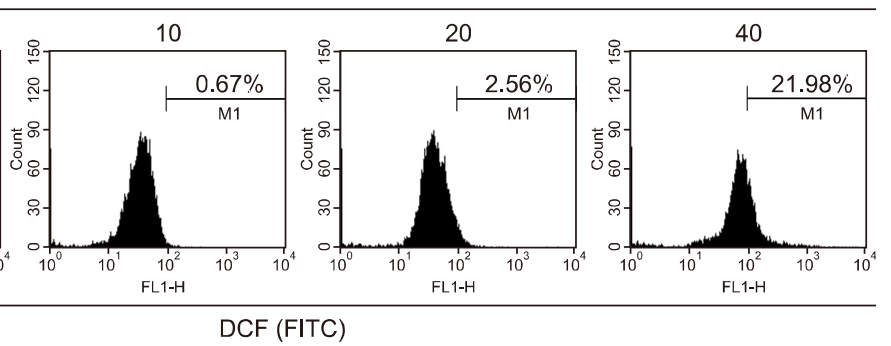

Fig. 4. Effect of harmine hydrochloride $(\mathrm{HMH})$ on apoptosis and reactive oxygen species (ROS) production in HCT116 cells. (A) Cells were treated with $\mathrm{HMH}(0,10,20$, and $40 \mu \mathrm{M})$ for $48 \mathrm{~h}$, stained with Annexin $\mathrm{V}$ and propidium iodide (PI), and analyzed using a FACSCalibur flow cytometer. (B) ROS production was measured by dichlorofluorescein (DCF) quantification in HCT116 cells exposed to $\mathrm{HMH}(0 \sim 40 \mu \mathrm{M})$ for $48 \mathrm{~h}$ using $\mathrm{H}_{2}$ DCFDA. Data are the mean \pm SD in triplicate tests. (C) Western blotting was performed to determine the expression of pro-apoptotic and anti-apoptotic proteins in HCT116 cells treated with HMH. $\beta$-Actin was used as an internal control. APC, allophycocyanin; FITC, fluorescein isothiocyanate.

p-cdc2, cdc2, and cyclin B1, which regulate the G2/M phase, in a dose-dependent manner (Fig. 3C). Additionally, $\mathrm{HMH}$ reduced expression of $\mathrm{Rb}$, a regulator of cell proliferation.

Because HMH was found to mediate cell cycle progression, we performed Annexin V-FITC/PI double staining to investigate whether HMH induces apoptosis. Treat- ment with 20 and $40 \mu \mathrm{M} \mathrm{HMH}$ increased the apoptotic cell population by $19.86 \%$ and $49.96 \%$, respectively (Fig. $4 \mathrm{~A})$. ROS production increased to $21.98 \%$ in the group treated with $40 \mu \mathrm{M} \mathrm{HMH}$ versus $1.09 \%$ in the control group (Fig. 4B). To investigate the mechanism underlying apoptosis, we performed Western blotting and examined the expression of apoptotic proteins such as caspase- 3 , 
A

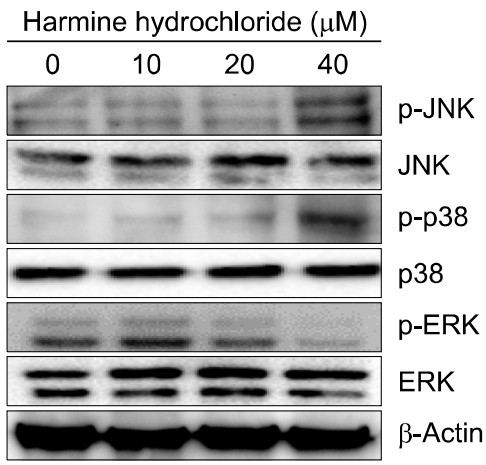

D

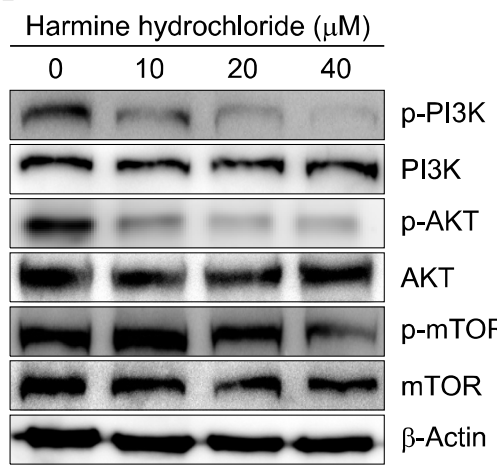

B
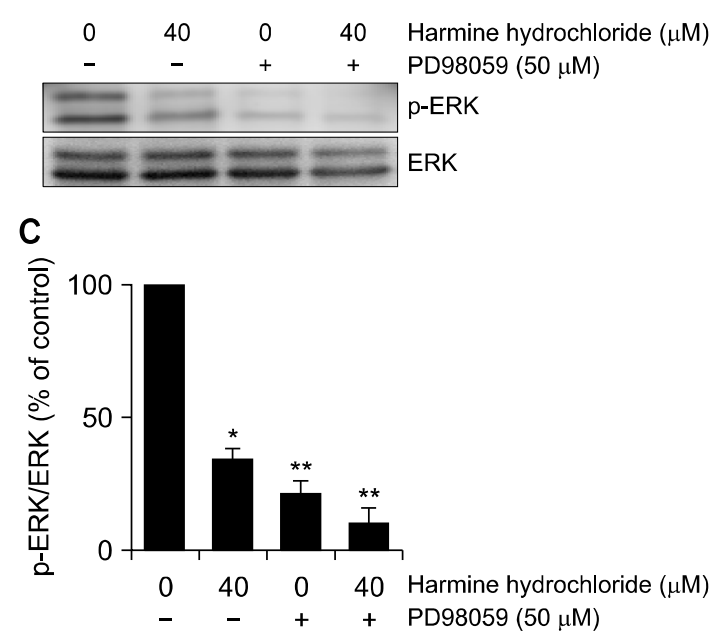

E
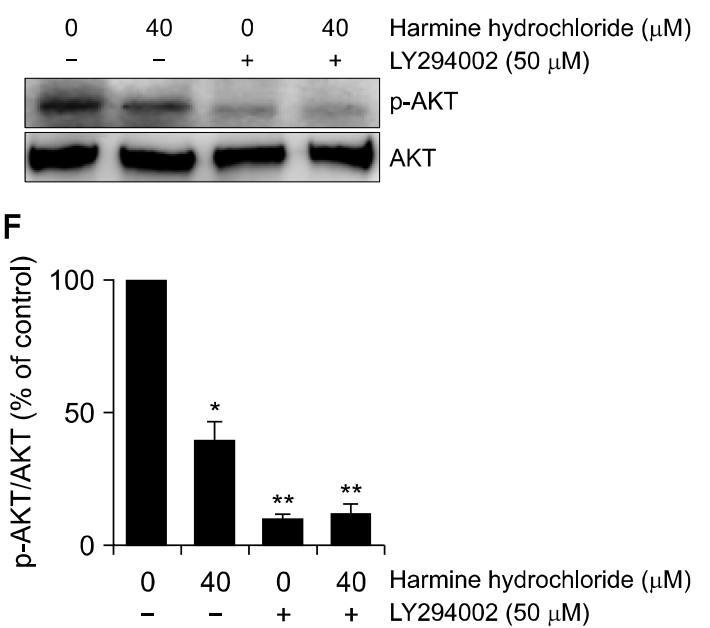

Fig. 5. Effect of harmine hydrochloride (HMH) on MAPK and PI3K/AKT/ mTOR signaling pathways. Representative blots showing the expression of MAPKs (A) and proteins associated with the PI3K/AKT/mTOR pathways (D). HCT116 cells were treated with 0 or $40 \mu \mathrm{M} \mathrm{HMH}$ in combination with the ERK inhibitor PD98059 (B) or the AKT inhibitor LY294002 (E). Expression of p-ERK and $p-A K T$ was examined by Western blotting. ( $C$ and F) Band intensity was normalized to total levels of ERK and AKT. Data are the mean \pm SD. ${ }^{*} P<0.05$ and ${ }^{* *} P<0.01$ compared with each total content. caspase-9, and PARP; the pro-apoptotic protein Bax; and the anti-apoptotic protein Bcl-2 (Fig. 4C). HMH reduced expression of apoptotic proteins such as pro-caspase- 3 , pro-caspase-9, and PARP, and the anti-apoptotic protein $\mathrm{Bcl}-2$ in a dose-dependent manner. In contrast, $\mathrm{HMH}$ increased expression of the pro-apoptotic protein Bax in a dose-dependent manner.

\section{$\mathrm{HMH}$ regulates ERK and PI3K/AKT/mTOR signaling pathways}

HMH increased expression of p-JNK and p-p38 and reduced expression level of p-ERK in a dose-dependent manner (Fig. 5A). Furthermore, p-ERK expression was significantly reduced in cells treated with the combination of PD98059 and HMH compared with control cells $(P<0.05$ and $P<0.01$, Fig. 5B and 5C). We investigated whether the PI3K/AKT/mTOR pathway was associated with the effect of HMH treatment on HCT116 cells (Fig. 5D). Western blotting was performed using proteins from HCT116 cells treated with 10,20 , and $40 \mu \mathrm{M} \mathrm{HMH}$ for $48 \mathrm{~h}$ to examine the inhibitory effect of $\mathrm{HMH}$ on protein expression. HMH reduced expression of p-PI3K, p-AKT, and p-mTOR. In addition, in cells were treated with a combination of LY294002 and HMH (Fig. 5E and 5F), HMH significantly reduced the activity of p-AKT $(P<0.05$ and $P<0.01)$. These results demonstrate that HMH inhibits cell proliferation and induces cell migration and apoptosis via ERK and PI3K/AKT/mTOR signaling pathways.

\section{DISCUSSION}

As interest in the development of novel natural productderived pharmaceuticals with anticancer activity increases, studies have explored the anticancer activities of betacarboline alkaloids, harmine, and harmine derivatives isolated from P. harmala L. seeds (Newman and Cragg, 2016). HMH has a similar structure to harmine, and both compounds possess identical pharmacological properties. HMH has excellent receptivity, and demonstrates anticancer activity against human gastric cancer cells and human hepatoma cells (Zhang et al., 2016; Tan et al., 2020). However, the mechanism of its anticancer activity toward CRC cells are unknown. In the present study, we dem- 
onstrated that $\mathrm{HMH}$ reduces cell viability and induces G2/M arrest and apoptosis in HCT116 cells. Cell cycle progression is characteristic of all eukaryotic cells. The cell cycle has four major checkpoints: the G1/S, S, G2/M, and spindle assembly (Sánchez and Dynlacht, 2005). Cyclins and cyclin-dependent kinase (CDK) complexes play an important role in regulating different stages of cell cycle progression. The G1 and S2 phases are regulated by CDK2, CDK6, CDK4, cyclin D1 and cyclin E, the G2/M phase is regulated by CDK2, cdc2, cyclin A, and cyclin B, and $\mathrm{G} 2 / \mathrm{M}$ transition is regulated by the cyclin $\mathrm{B} / \mathrm{cdc} 2$ complex. A CDK inhibitor $\mathrm{p} 21^{\text {Wafl/Cip1 }}$ has been shown to inactivate the cyclin $\mathrm{B} 1 / \mathrm{cdc} 2$ complex in p53-dependent sustained G2/M arrest (Smith et al., 2020). We showed that HMH induces G2/M cell cycle arrest, significantly upregulates $\mathrm{p} 53$ and $\mathrm{p} 21$ protein expression, and downregulates cyclin $\mathrm{B} 1, \mathrm{p}-\mathrm{cdc} 2$, and cdc2 expression in HCT 116 cells.

Apoptosis is a type of programmed cell death that occurs under normal physiological or pathological conditions, and is induced via various pathways, including the death receptor and mitochondrial pathways, and during endoplasmic reticulum stress (Iurlaro and Muñoz-Pinedo, 2016). Various factors of the mitochondrial apoptosis pathway downregulate pro-survival proteins and upregulate pro-apoptotic proteins, reducing mitochondrial membrane potential and inducing cytochrome $\mathrm{c}$ release from mitochondria. Cytochrome $\mathrm{c}$ induces apoptosis within the cytoplasm by activating caspase- 9 and caspase- 3 and promoting PARP degradation (Gogvadze et al., 2009). Bcl-2 family proteins play an important role in regulating apoptosis (Zhou et al., 2011). Apoptosis occurs when expression of anti-apoptotic proteins in the mitochondrial membrane, such as Bcl-2 and Bcl-xL, decrease and the ratio of pro-apoptotic proteins such as Bax (Bcl-2/Bax, Bcl$\mathrm{xL} / \mathrm{Bax}$ ) relatively reduce, increase, or remain unchanged. In the present study, flow cytometry analysis showed a dose-dependent increase in the proportion of apoptotic HCT116 cells. Western blotting results confirmed that HMH reduced expression of pro-caspase-3, pro-caspase9, PARP, and Bcl-2 and increased expression of Bax, consequently inducing apoptosis.

ROS plays an important role in apoptosis. Cancer cells appear to have high levels of endogenous oxidative stress, and cancer cell growth can be inhibited by increasing ROS production (Chen et al., 2017). Under pathological conditions, excessive ROS damages DNA, proteins, mitochondria, and the endoplasmic reticulum, and induces cell cycle arrest and apoptosis (Simon et al., 2000). In our study, $\mathrm{HMH}$ increased ROS production in a dose-dependent manner.

JNK and p38 MAPK play important roles in the regulating apoptosis and autophagy (Brancho et al., 2005; Dha- nasekaran and Reddy, 2008). Activated JNKs are translocated to the mitochondria, where they phosphorylate the anti-apoptotic proteins $\mathrm{Bcl}-2$ and $\mathrm{Bcl}-\mathrm{xL}$, reduce expression of the isomers $\mathrm{Bax}, \mathrm{Bcl}-2$, or $\mathrm{Bcl}-\mathrm{xL}$, and separate Bax to induce cell apoptosis (Jeong et al., 2008). Activated EPKs induce apoptosis in response to a wide range of stimuli. Indeed, ERKs inhibit pro-apoptotic proteins such as caspase-8, caspase- 9 , Bad, Bim, and signal transducer and activator of transcription $3 / 5$, and activate anti-apoptotic proteins such as Bcl-xL, c-Flip, immediate early response gene X-1, and cAMP-response elementbinding protein through phosphorylation. Similar to AKTs, activated ERKs regulate many cellular events, including cell proliferation and survival (Peng et al., 2010; Samatar and Poulikakos, 2014). In this study, we found that HMH upregulates ERKs and downregulates proteins associated with cell cycle arrest and mitochondrial apoptosis. Western blotting results showed that HMH upregulates p-JNK and p-p38 expression and downregulates p-ERK expression in HCT116 cells; thus, HMH inhibites ERK expression and induced cell apoptosis.

AKT signaling induces cell proliferation and apoptosis, and regulates expression of apoptotic proteins, such as the Bcl-2 family proteins (Zhang et al., 2015). In this study, we demonstrated that inactivation or inhibition of the PI3K/AKT/mTOR pathway leads to downregulation of cyclin B1 and cdc2 expression and, subsequently, G2/M cell cycle arrest.

In the present study, HMH inhibited the growth of human CRC HCT116 cells by inducing cell cycle arrest and apoptosis, reduced the proportion of cells in the G0/G1 phase, and increased the proportion of cells in the G2/M phase. Additionally, HMH induced apoptosis by regulating expression of the Bcl-2 family genes and mitochondrial proteins and, in combination with ERK or AKT inhibitors, reduced p-ERK and p-AKT expression. These results demonstrated that ERK and $\mathrm{PI} 3 \mathrm{~K} / \mathrm{AKT} / \mathrm{mTOR}$ pathway inhibition may be involved in $\mathrm{HMH}$-induced cell cycle arrest and apoptosis in HCT116 cells. The results of our study indicate the potential therapeutic application of $\mathrm{HMH}$ in $\mathrm{CRC}$ treatment.

\section{ACKNOWLEDGEMENTS}

This work was supported by National Research Foundation of Korea (NRF) grant funded by the Korea government (MSIT) (grant number 2020R1F1A1072191).

\section{AUTHOR DISCLOSURE STATEMENT}

The author declares no potential conflict of interest. 


\section{REFERENCES}

Arthur JS, Ley SC. Mitogen-activated protein kinases in innate immunity. Nat Rev Immunol. 2013. 13:679-692.

Bahrami A, Khazaei M, Hasanzadeh M, ShahidSales S, Joudi Mashhad M, Farazestanian M, et al. Therapeutic potential of targeting PI3K/AKT pathway in treatment of colorectal cancer: rational and progress. J Cell Biochem. 2018. 119:24602469.

Brancho D, Ventura JJ, Jaeschke A, Doran B, Flavell RA, Davis RJ. Role of MLK3 in the regulation of mitogen-activated protein kinase signaling cascades. Mol Cell Biol. 2005. 25:3670-3681.

Chen X, Dai X, Zou P, Chen W, Rajamanickam V, Feng C, et al. Curcuminoid EF24 enhances the anti-tumour activity of Akt inhibitor MK-2206 through ROS-mediated endoplasmic reticulum stress and mitochondrial dysfunction in gastric cancer. Br J Pharmacol. 2017. 174:1131-1146.

Das Thakur M, Stuart DD. Molecular pathways: response and resistance to BRAF and MEK inhibitors in BRAF(V600E) tumors. Clin Cancer Res. 2014. 20:1074-1080.

Dhanasekaran DN, Reddy EP. JNK signaling in apoptosis. Oncogene. 2008. 27:6245-6251.

Gogvadze V, Orrenius S, Zhivotovsky B. Mitochondria as targets for cancer chemotherapy. Semin Cancer Biol. 2009. 19:57-66.

Golob-Schwarzl N, Krassnig S, Toeglhofer AM, Park YN, GoggKamerer M, Vierlinger K, et al. New liver cancer biomarkers: $\mathrm{PI} 3 \mathrm{~K} / \mathrm{AKT} / \mathrm{mTOR}$ pathway members and eukaryotic translation initiation factors. Eur J Cancer. 2017. 83:56-70.

Iurlaro R, Muñoz-Pinedo C. Cell death induced by endoplasmic reticulum stress. FEBS J. 2016. 283:2640-2652.

Jeong HS, Choi HY, Choi TW, Kim BW, Kim JH, Lee ER, et al. Differential regulation of the antiapoptotic action of B-cell lymphoma 2 (Bcl-2) and B-cell lymphoma extra long (Bcl-xL) by c-Jun N-terminal protein kinase (JNK) 1-involved pathway in neuroglioma cells. Biol Pharm Bull. 2008. 31:1686-1690.

Kang DW, Lee BH, Suh YA, Choi YS, Jang SJ, Kim YM, et al. Phospholipase D1 inhibition linked to upregulation of ICAT Blocks colorectal cancer growth hyperactivated by Wnt/ $\beta$-catenin and PI3K/Akt signaling. Clin Cancer Res. 2017. 23:7340-7350.

Kuebler JP, Wieand HS, O'Connell MJ, Smith RE, Colangelo LH, Yothers G, et al. Oxaliplatin combined with weekly bolus fluorouracil and leucovorin as surgical adjuvant chemotherapy for stage II and III colon cancer: results from NSABP C-07. J Clin Oncol. 2007. 25:2198-2204.

Liu H, Han D, Liu Y, Hou X, Wu J, Li H, et al. Harmine hydrochloride inhibits Akt phosphorylation and depletes the pool of cancer stem-like cells of glioblastoma. J Neurooncol. 2013. 112: 39-48.

McChesney JD. Natural products in drug discovery-organizing for success. P R Health Sci J. 2002. 21:91-95.

Mukherjee AK, Basu S, Sarkar N, Ghosh AC. Advances in cancer therapy with plant based natural products. Curr Med Chem. 2001. 8:1467-1486.

Murthy D, Attri KS, Singh PK. Phosphoinositide 3-kinase signaling pathway in pancreatic ductal adenocarcinoma progression, pathogenesis, and therapeutics. Front Physiol. 2018. 9:335. https://doi.org/10.3389/fphys.2018.00335

Newman DJ, Cragg GM. Natural products as sources of new drugs from 1981 to 2014. J Nat Prod. 2016. 79:629-661.

Papadatos-Pastos D, Rabbie R, Ross P, Sarker D. The role of the PI3K pathway in colorectal cancer. Crit Rev Oncol Hematol. 2015. 94:18-30.

Peng S, Zhang Y, Zhang J, Wang H, Ren B. ERK in learning and memory: a review of recent research. Int J Mol Sci. 2010. 11: 222-232.

Peti W, Page R. Molecular basis of MAP kinase regulation. Protein Sci. 2013. 22:1698-1710.

Qin H, Liu L, Sun S, Zhang D, Sheng J, Li B, et al. The impact of PI3K inhibitors on breast cancer cell and its tumor microenvironment. PeerJ. 2018. 6:e5092. https://doi.org/10.7717/ peerj.5092

Sabio G, Davis RJ. TNF and MAP kinase signalling pathways. Semin Immunol. 2014. 26:237-245.

Samatar AA, Poulikakos PI. Targeting RAS-ERK signalling in cancer: promises and challenges. Nat Rev Drug Discov. 2014. 13:928-942.

Sánchez I, Dynlacht BD. New insights into cyclins, CDKs, and cell cycle control. Semin Cell Dev Biol. 2005. 16:311-321.

Simon HU, Haj-Yehia A, Levi-Schaffer F. Role of reactive oxygen species (ROS) in apoptosis induction. Apoptosis. 2000. 5:415418.

Smith HL, Southgate H, Tweddle DA, Curtin NJ. DNA damage checkpoint kinases in cancer. Expert Rev Mol Med. 2020. 22:e2. https://doi.org/10.1017/erm.2020.3

Tan B, Li Y, Zhao Q, Fan L, Zhang M. The impact of harmine hydrochloride on growth, apoptosis and migration, invasion of gastric cancer cells. Pathol Res Pract. 2020. 216:152995. https://doi.org/10.1016/j.prp.2020.152995

Torre LA, Bray F, Siegel RL, Ferlay J, Lortet-Tieulent J, Jemal A. Global cancer statistics, 2012. CA Cancer J Clin. 2015. 65:87108.

Turjanski AG, Vaqué JP, Gutkind JS. MAP kinases and the control of nuclear events. Oncogene. 2007. 26:3240-3253.

Yoon DS, Lee MH, Cha DS. Measurement of intracellular ROS in Caenorhabditis elegans using 2',7'-dichlorodihydrofluorescein diacetate. Bio Protoc. 2018. 8:e2774. https://doi.org/10. 21769/BioProtoc. 2774

Zhang J, Yu XH, Yan YG, Wang C, Wang WJ. PI3K/Akt signaling in osteosarcoma. Clin Chim Acta. 2015. 444:182-192.

Zhang L, Li D, Yu S. Pharmacological effects of harmine and its derivatives: a review. Arch Pharm Res. 2020. 43:1259-1275.

Zhang P, Huang CR, Wang W, Zhang XK, Chen JJ, Wang JJ, et al. Harmine hydrochloride triggers $\mathrm{G} 2$ phase arrest and apoptosis in MGC-803 cells and SMMC-7721 cells by upregulating p21, activating caspase-8/Bid, and downregulating ERK/Bad pathway. Phytother Res. 2016. 30:31-40.

Zhou F, Yang Y, Xing D. Bcl-2 and Bcl-xL play important roles in the crosstalk between autophagy and apoptosis. FEBS J. 2011. 278:403-413. 